\title{
Entanglements with Reggio in Northern Ontario, Canada
}

\author{
Julie Kelly, Sophie Anne Edwards, and Sharon Speir
}

\begin{abstract}
Julie Kelly is a teacher in a French immersion kindergarten classroom in the Rainbow District School Board, Ontario, Canada. She has worked in education for 22 years, most of them in an early learning setting. She is committed to mentoring other educators interested in emergent learning and research with children. Julie's study of the Reggio Emilia approach has deepened her relationship with materials and the children and families she has worked alongside. As a teacher-researcher, she is always looking at children's work for meaning and a deeper understanding of how they think, interpret, and understand the world about them.

Email: kellyj@rscloud.ca
\end{abstract}

Sophie Anne Edwards is an environmental artist, writer, and independent scholar whose work centers around site-specific, placebased, and creative field research. Her work has been supported by the Ontario Arts Council, and she earned a Community Service Learning Award (with Dr. Neal Scott, Queen's University) for an interdisciplinary land use history project. She is the lead author and editor of the two-volume The Art of Land-based Early Learning, which highlights her holistic, environmental approach to Reggiobased work with children, along with the experiences of artist-educators, teachers, and early learning educators from northeastern Ontario. She has a certificate in creative writing (Humber College), an interdisciplinary master's (Laurentian University) and a PhD (ABD, Queen's University). She is based on Mnidoo Mnising (Manitoulin Island), Ontario, Canada.

Email: sophieanneedwards@gmail.com

Sharon Speir, PhD, is an early childhood collaborator, researcher, and storyteller who is inspired by the children, educators, and artists of Reggio Emilia, Ontario, and Bermuda. Formerly a superintendent with the Rainbow District School Board responsible for early learning and the assistant director of early childhood with the Ministry of Education in Bermuda, she is one of the regional coordinators for the Sudbury district, assisting in building a network of pedagogical support for early childhood educators across Ontario, Canada. Her research interests include pedagogical documentation and narrative and place-based inquiry.

Email: sharonspeir@gmail.com

In the fall and spring, water beckons to us to "jump the fence" and follow the pathways created by seasonal water changes within the watershed. Inspired by Reggio Children's Dialogues with Places and their pedagogies of listening and relationality, we wonder how paying attention to water might open a different, imaginative space as we question our ongoing colonial relationships with land and water intended to keep water at a distance. Through photos and artwork, we make visible some of the dialogic and empathetic relationships between children and water while making the case that these Reggio principles are relevant to our engagements with children and place.

Key words: dialogue with place; relationality; listening; reconciliation

how we are situated with the land, the trees, and the water in northern Ontario, Canada:

\section{Reggio inspiration and invention: A dialogue with place}

Every encounter that we have had with Reggio educators starts with a description of how they are located, where they come from, their values, and their relationships with the community in which they live. This "being located" appears to be fundamental to understanding their context and the values that spring from that particular context. Reggio educators tell us we cannot "do Reggio" in North America, that we have to understand and work with our own local context and our values. So where do we begin? We have found that Reggio-inspired "dialogues with place" and pedagogies of relationality and listening resonate with our values and the places where we live, and have changed and sometimes disrupted our thinking about how we encounter place with children.

From Reggio Children's Dialogues with Places comes a provocation that prompts us to think about our relationship to place. We extend this prompt to consider 
Every place has a soul, an identity, and seeking to discover it, and relate to it, means learning to recognize your own soul as well. More and more we are witnessing an apathetic and fossilized acceptance of vulgarity and ugliness, of the lack of care for the environment in which we live. It is the responsibility of education, as well, to contrast this tendency that jeopardizes, at both the individual and social levels, the quality of our current and future lives. (Reggio Children, 2008, p. 11)

R. L. Beattie Public School, where this story begins, is located in Greater Sudbury, an amalgamated municipality in northeastern Ontario surrounded by a rugged and beautiful Canadian Shield landscape with windswept pines and an integrated system of waterways that includes 330 lakes. This land, however, was ravaged by the clear-cutting of forests and the mining and smelting of nickel that began in 1888. For the past eight years, Julie, Sophie, and Sharon have been studying Reggio and thinking about what values shape our northern Ontario sensibility, especially in the context of early education, and how we might engage with children in a dialogue with this place and its identity.

The bush that borders the school playground reflects the difficult history of colonialism in Canada. The land is on the traditional territory of the Atikameksheng Anishnawbek, which was claimed by Canada through the Robinson Treaty. Now this bush is in a residential suburb in a city, and while it is full of natural life, it also contains humanmade refuse dumped from recent building construction and late-night visitors (plastic containers, pop cans). The movement of water in this territory has changed due to land use and construction, including housing, the school, and the surrounding neighbourhood.

On a winter day, Zoe discovers a plastic container buried in the snow and tries to pull it out. Her friends join in and they try different ways to move it, pushing, stamping on it, and using a stick to try to pry it loose, with no result. As the others drift away, Zoe persists. "I would do anything to save Mother Earth," she exclaims.

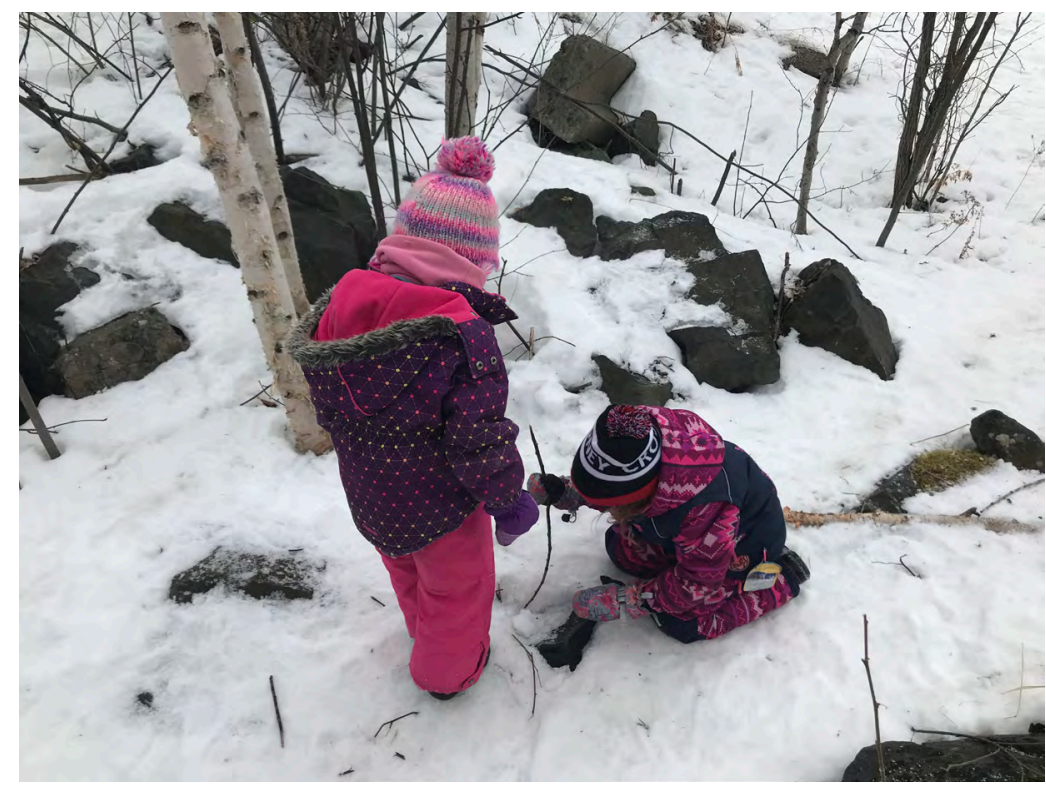

Figure 1. Using a stick, Zoe tries to pry a discarded container from the ice.
In the spring, the children drift toward large pools of water above the height of their rubber boots, toward random sinkholes that appear overnight in the playground. Adults are quick to intervene, cordoning off danger zones with orange pylons. Julie, their teacher, pushes against this dominant and distancing discourse, however. She is intrigued by the children's questions: Where does the water come from? Where it is going? Deciding to follow the water's lead, and the children's questions, into the bush, she invites environmental artist Sophie Anne Edwards to help the children document their thinking using different art media, and asks Sharon Speir to document the process.

This venture into the bush is an apt metaphor for our journey with Reggio: uncharted, unmapped, and often full of uncertainty; it is most certainly a dialogue with place. Loris Malaguzzi (1994) writes about education as a metaphorical forest, a place of encounters:

Living together in this forest ... is important. And this living together is not easy. We have to find each other in the forest and begin to discuss what the education of the child actually means. The important aspect is not just to promote the education of the child but the health and happiness of the child as well. (p. 2) 

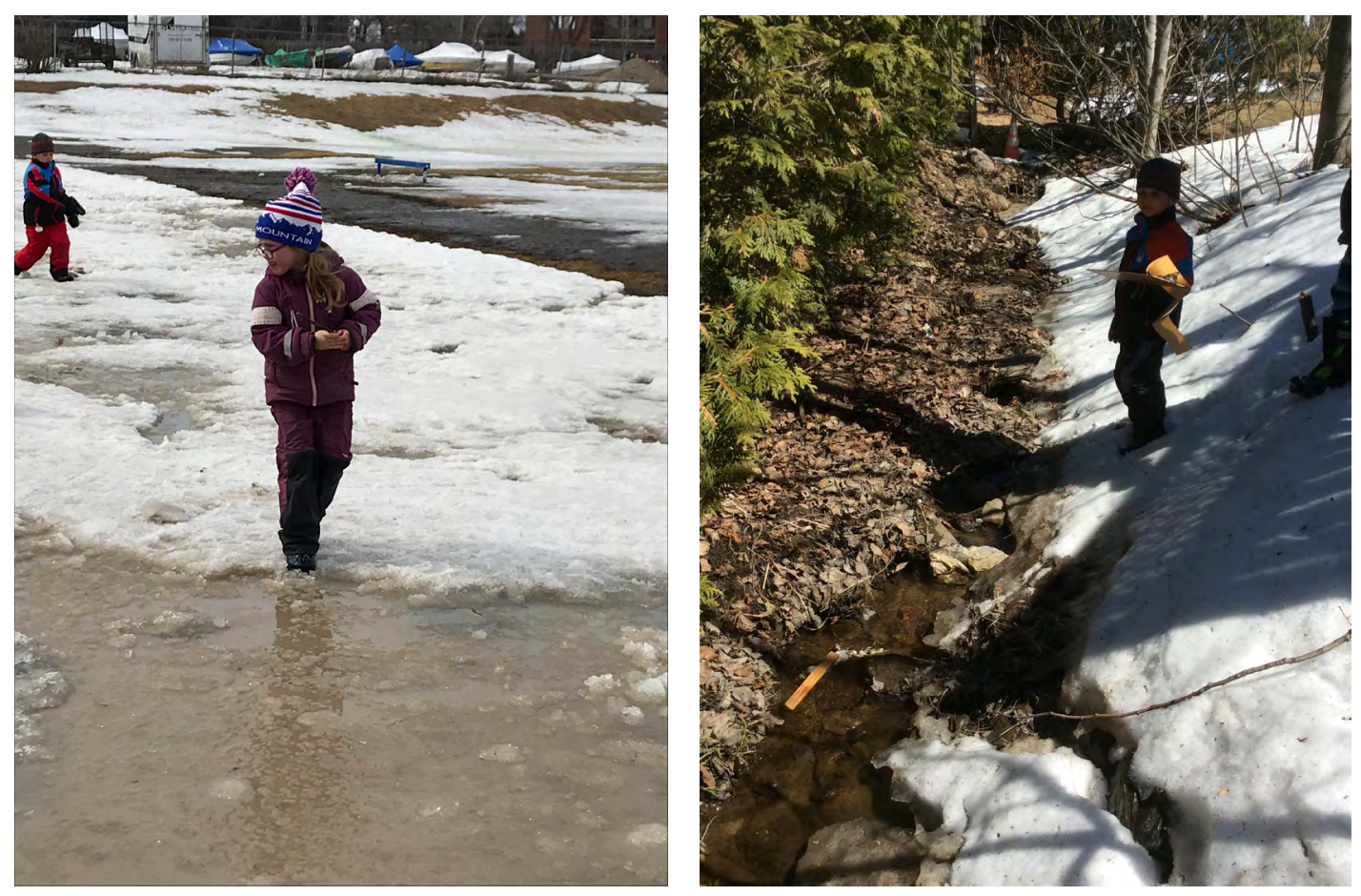

Figure 2. The children follow water in the playground and the creek behind the school.

Our experience of place-and with our following of questions, following paths, and taking nature's lead-is that a dialogue with place is distinctly relevant to our location, and that "meeting in the forest" that is education is important for the child, the educators, and the land itself.

\section{Dialogues in the bush: Encountering the other (human and nonhuman)}

Malaguzzi (as quoted by Filippini, 2018) points to all our interconnected relations:

We are-and we must be convinced-within an ecosystem: our earthly journey is a journey that goes hand in hand with the environment, nature, cosmos; the organism, our morality, our culture, our knowledge, our feelings connect with the environment, with the universe, with the world. And here's the web of our life.

This pedagogy of relationality to which Malaguzzi refers is where children's competencies are evident (Filippini, 2018). We see an emerging agency in children to treat the land as sacred. In many ways, children want to change what they see, redeem the devastation of human impact and be part of the reconceptualization of place. Throughout the week we were together, the children continuously found different avenues to be advocates for the land they play on. Relationships and competencies emerged, not only between educators and children and between children, but between children and place. The children's capacity to listen to and learn from place grew and emerged from our encounters with Reggio and with place.

What does it mean to listen to place? What kind of relationships and dialogues do children establish with water through this encounter with place? How do their explorations differ on the playground and in the bush? We tend to think primarily of the education of the child, but we must also understand that how we learn and engage is also about the land and place with which we learn. 
Astrida Neimanis (2012) challenges us to think with water as a collaborator in this process. She invites us to "really pay attention to it-how it moves, what it does, what it is threatened by, how it organizes itself and other bodies" (p. 2) in order to disrupt dominant discourses that have shaped our perceptions of water and land, and to open to new and imaginative spaces.

In the spring, Neimanis (2012) writes, "water quite literally disturbs the solidity of the ground underneath one's feet" (p. 13). We have to be careful where we step, how we proceed in the playground and in the bush. The ice that had turned the creek into a frozen walkway is melting, and the ground quite literally moves under our feet. Sometimes our boots sink deep into the mud and sometimes we feel the ground supporting us.
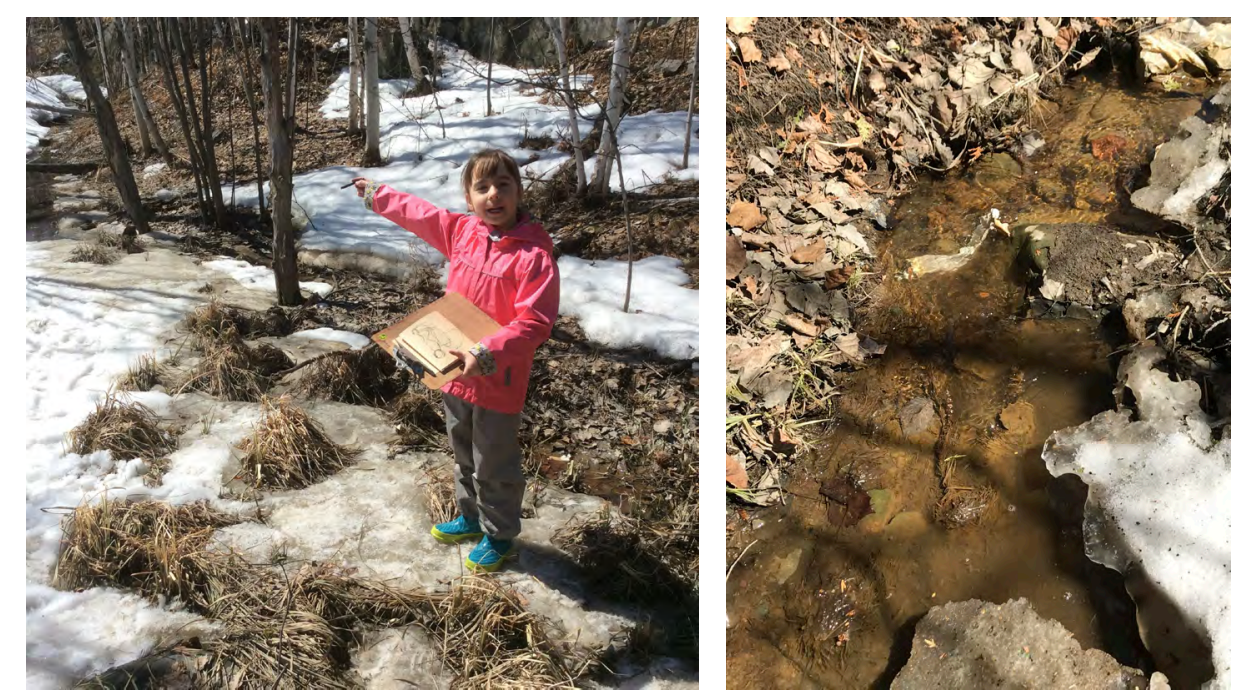

Figure 3. June, pointing down the stream: "It was a puddle that then went into a stream. Then it went under the ice chunk and then under another ice chunk. It was a puddle that went all the way along."

Neimanis (2012) points out that "water babbles in languages we do not fully comprehend ... we might do better just to listen" (p. 13). Malaguzzi views children as capable of communicating in a hundred languages (Edwards, Gandini, \& Forman, 1998, pp. 2-3). We see them as attuned to how water speaks; given the opportunity, they express what they hear, and we see this in their actions and their drawings.

In the children's drawings, we observe their deep observation and their listening to this encounter with water. The image (above, left) is a representation of a frozen tire the children found encased in ice. Back in the classroom, this piece of garbage serves as a catalyst for Finn to imagine a machine that can make clouds. He reconceptualizes the tire on the paper and with materials in a three-dimensional form. He does not see the tire as debris but rather as an opportunity for reconsidering its purpose.

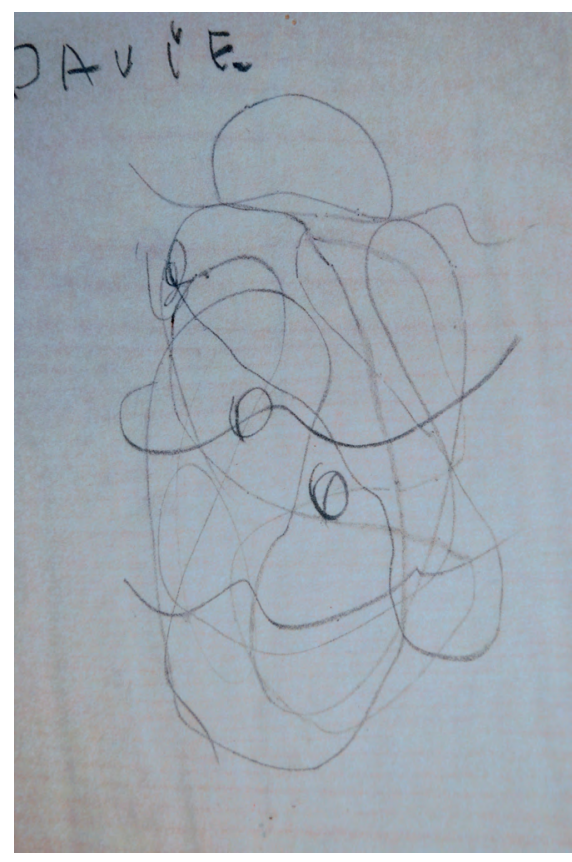

Figure 4. Observational drawing of melted ice by Davie. 

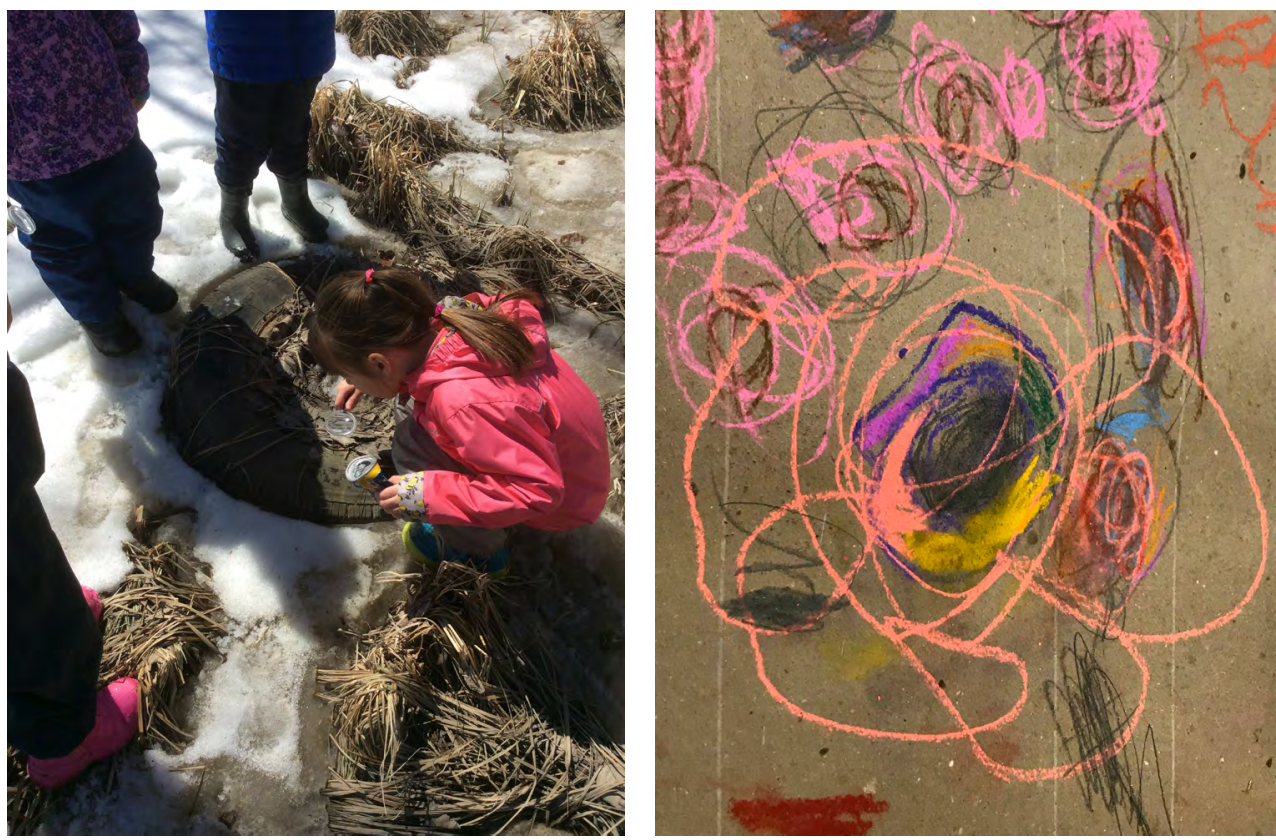

Figure 5. Left, a frozen tire encased in ice found by the children; right, collaborative drawing of same.

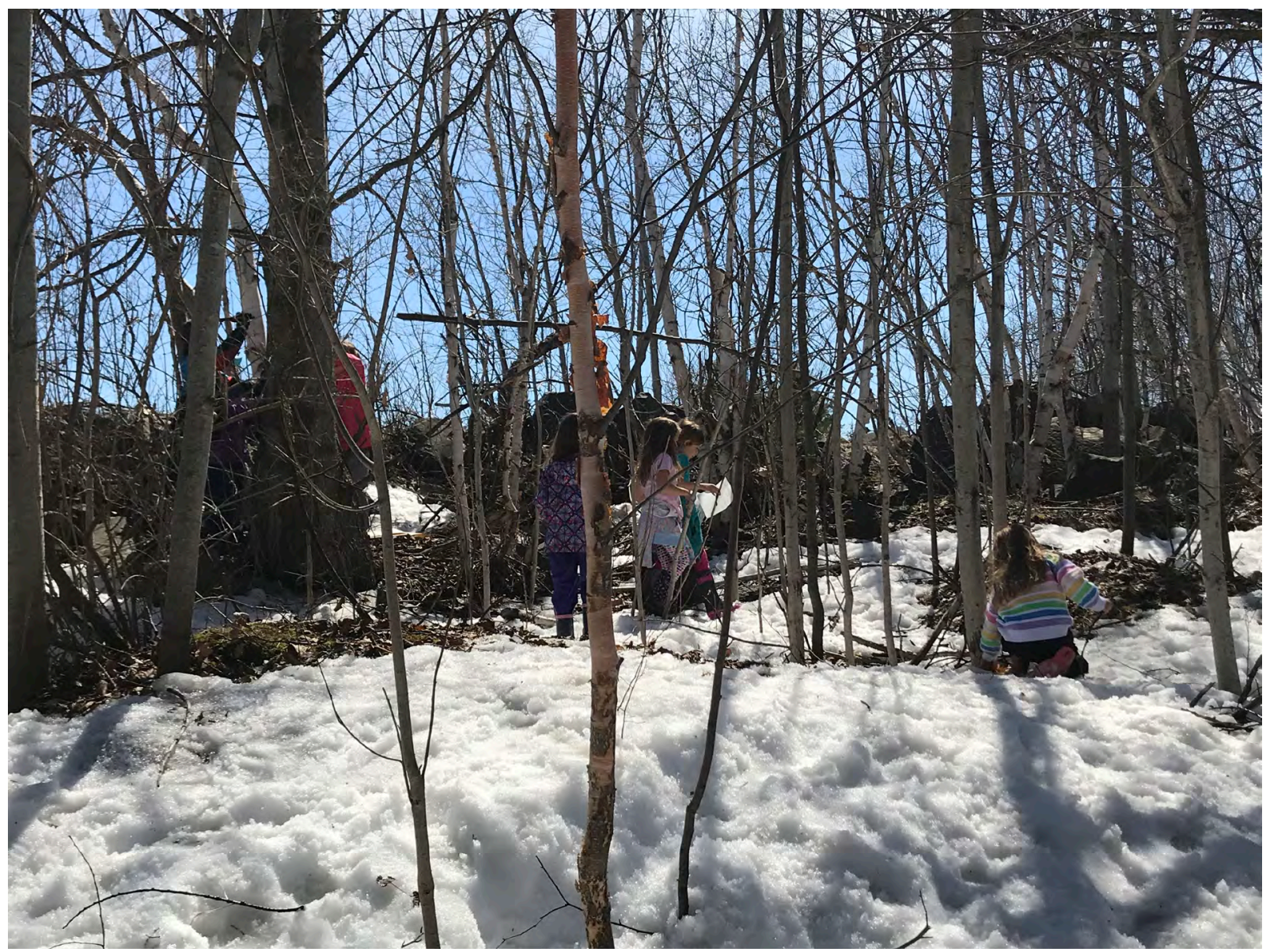

Figure 6. In the bush we see a different child. 


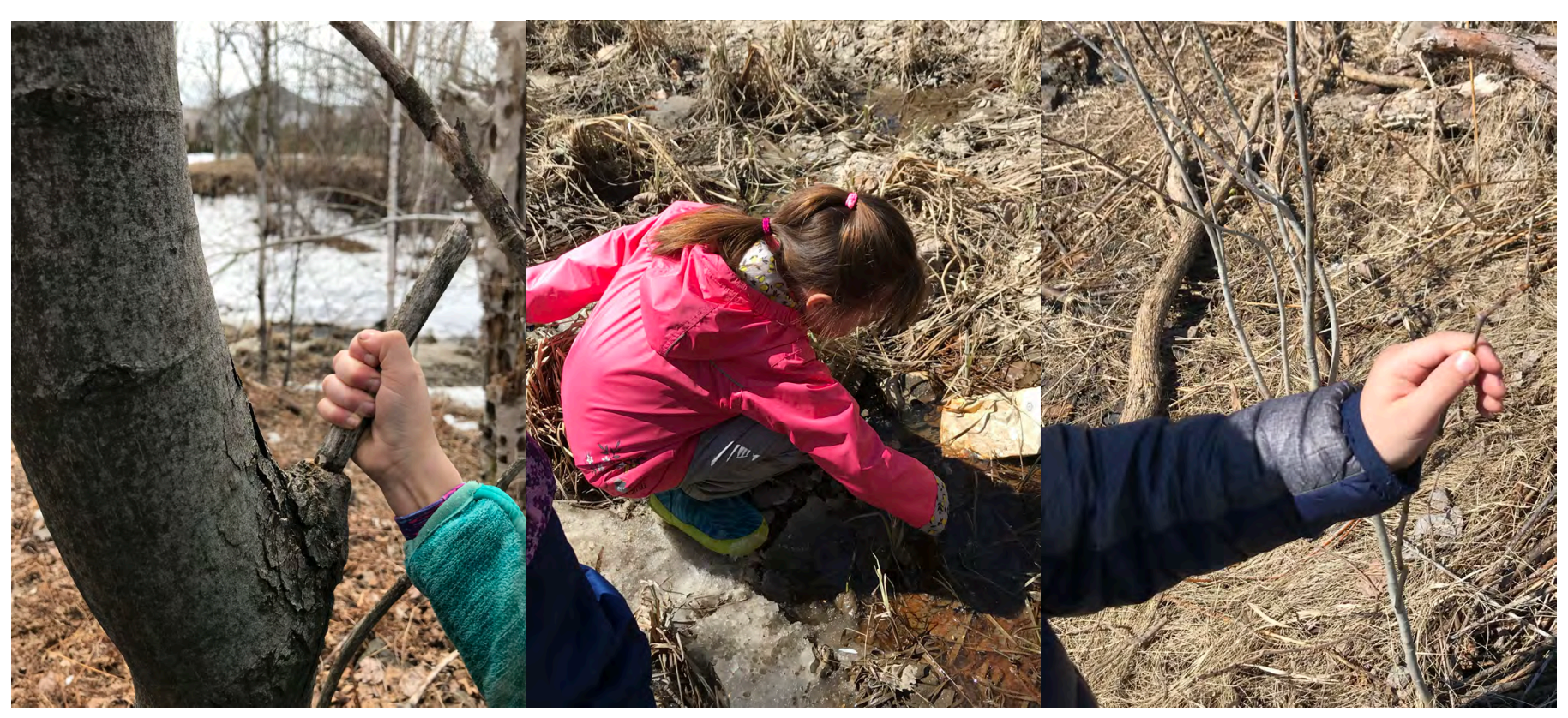

Figure 7. The children slow down, pause, touch, consider, lean into nature.

In the bush, we see a different child from the child indoors, from the child on the playground; here the children's movements slow down. They pause, touch, consider ... they lean into nature. The trees become the means by which they can walk up the steep hill, the rocks a pathway to get across the creek. They follow the contours of the land and learn from it through this following. In the schoolyard the built environment directs our feet, but in the bush the land leads us. Feet follow river pathways; they balance on chunks of ice. We see hands that hold, that touch, fingers that point, that track, that draw, that outline the way the water goes. Sophie encourages this embodied listening by asking the children to draw what they notice. To follow the pathways. Touch the bark. Smell the buds. Gilles Deleuze (1994, as cited in Dahlberg \& Moss, 2004) put it this way: "Thought is what confronts us from outside, unexpectedly. Something in the world forces us to think. This something is an object not of recognition but of fundamental encounter" (p. 114). 


\section{In search of water pathways}
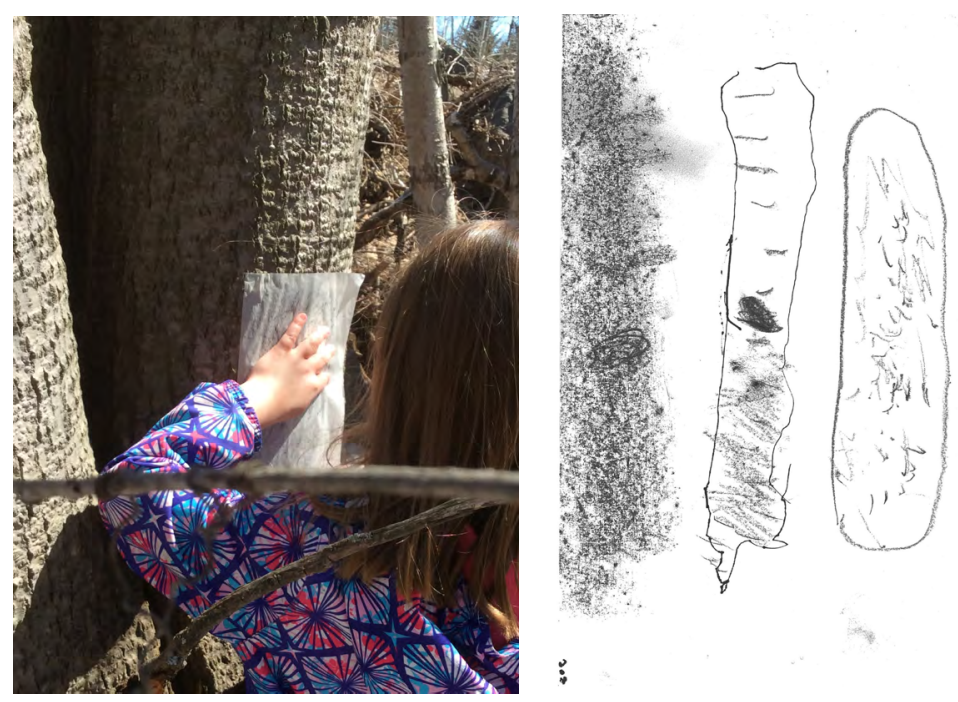

Figure 8. Bark rubbing (left) and bark drawings (right) by Zoe. Where does water go? How does it get to the leaves? Does water move through wood?
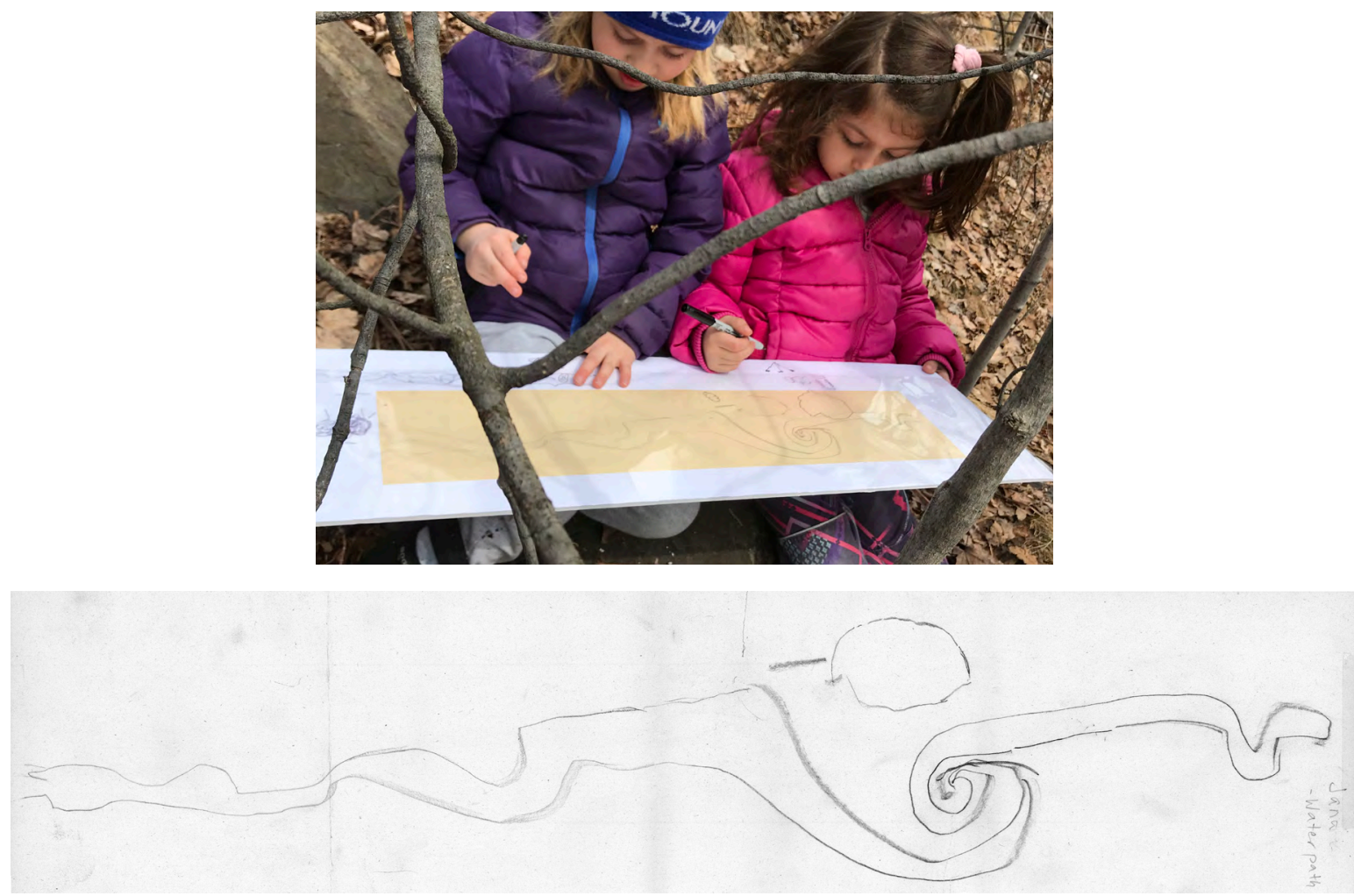

Figure 9. Water pathways on the ground, by Davie and Jana. 


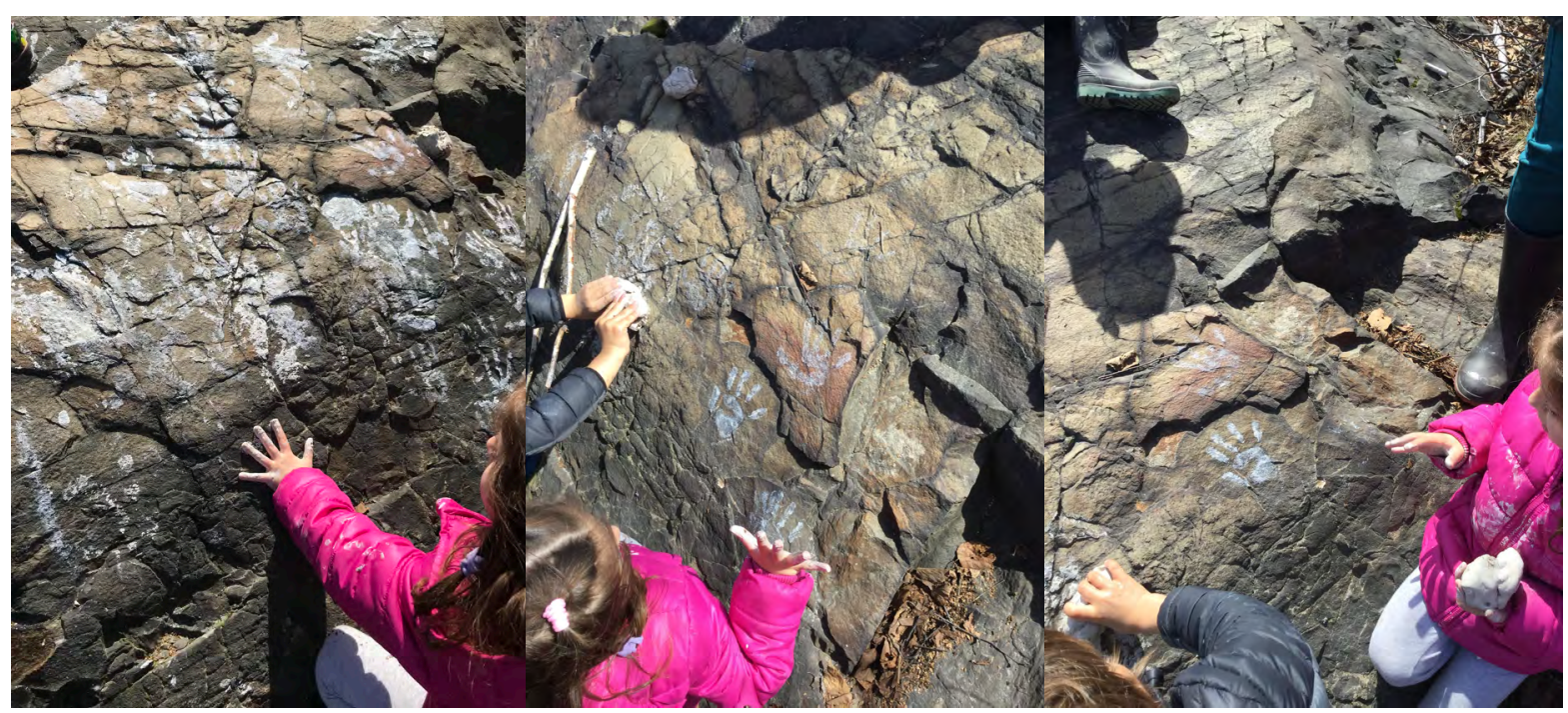

Figure 10. Hand, clay, and water pathways-impressions on rock.

It's making a pathway in the rocks, it goes through the cracks. (Kale)

It's a hand pathway ... you can follow it.

It is through this embodied listening that children connect to the land and the water.

Rinaldi (2001, as cited in Dahlberg \& Moss, 2005) describes Reggio's understanding of listening as

sensitivity to the patterns that connect, to that which connects us to others, abandoning ourselves to the conviction that our understanding and our own being are but small parts of a broader, more integrated knowledge that holds the universe together. (p. 99)

Through the children's drawings, we see children listening to the water and to the land. We notice their sensitivity to the patterns that connect us, not in a way that assumes the other-water and land-is like us, but following Deleuze's idea of a fundamental encounter with the Other, one that changes us.

This listening that follows the lead of the water and the land is not possible from a removed distance; it requires hands on, feet on, and bodies engaged. Reggio Children (2008) write, "One perceives their empathy with the surroundings" (p. 22) through the gestures that children express through art, through their hands and their bodies.

These drawings indicate to us that the children recognize the larger scheme of things-that they are part of the pathway-that pathways are alive-that pathways are connected and interconnected. As Henry concludes during a circle discussion with their teacher, Julie, "Everything is a pathway!" "Yes," Mira confirms, "the whole world is a pathway."

The children's lively engagement with pathways and their creative, holistic responses support what Reggio educators in Dialogues with Places concluded:

The children's experience elicited empathetic, creative and cognitive processes, and generated project hypotheses aimed at opposing widespread attitudes of disengagement and indifference as well as passive and non-critical acceptance as spaces void of quality. (Reggio Children, 2008, p. 11) 


\section{Encounters with Reggio: Encounters with pedagogy}

Listening to children, and to the water, requires a particular kind of presence on the part of the teacher, artist, and documenter. Malaguzzi (1994) advises:

We need to know how to recognize a new presence, how to wait for the child. This is something that is learned, it's not automatic. We often have to do it against our own rush to work in our own way. We'll discover that our presence, which has to be visible and warm, makes it possible for us to try to get inside the child and what that child is doing. And this may seem to be passive, but it is really a very strong activity on our part. (p. 2)

We think of listening as being present, attending to, taking direction from and responding to, being in dialogue with the children, the water, and the land. As educators, our listening to the children creates the space for their listening, in this case to the land and to the water. The role of the teacher in an emergent-inquiry stance is often interpreted as a passive one: waiting for something to happen. Through our work, however, we have come to see the teacher's role as active and intentional, making choices based on what she has noticed and observed, what she has documented, what she will follow up on, and which questions and pathways are worthwhile learning experiences. Expanding the arts in school beyond a lesson or activity can open into a way of seeing the world, an opportunity to engage with issues, to change the way we think, the way we communicate, to take a stance on particular problems and issues we encounter in the world. Having a big research question and an inquiry methodology also helps drive the work, away from a product toward a process that engages children in the act of creation. In this way, the arts and art media can become a vehicle for listening, and a way for children to document encounters and relationships.

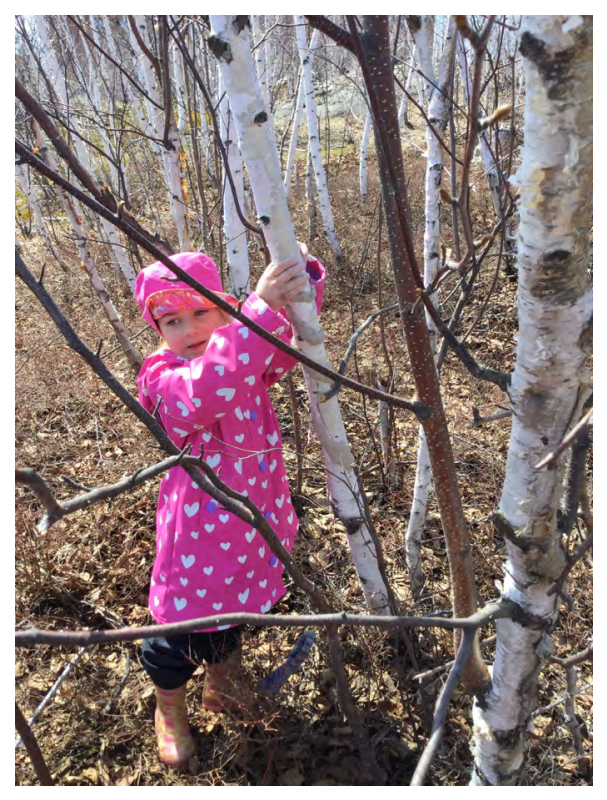

Figure 11. A pathway with clay up the tree by Ava.

It is here in this space-in our encounter with the land-that we also begin to understand why Reggio educators emphasize a dialogue with place and see the environment (or context) acting as a third teacher. Within our context, the environment often extends far beyond the classroom into the local ecosystem. This northern landscape has lots to say, and the children are listening.

A relational ecological approach coupled with an embodied practice connect hand and land, heart and place, mind and the natural world, moving us toward a cultural shift that understands our place in the world as relational and interdependent rather than dominant and separate: We are in the world, not observing it (Edwards, 2017, p. 20).

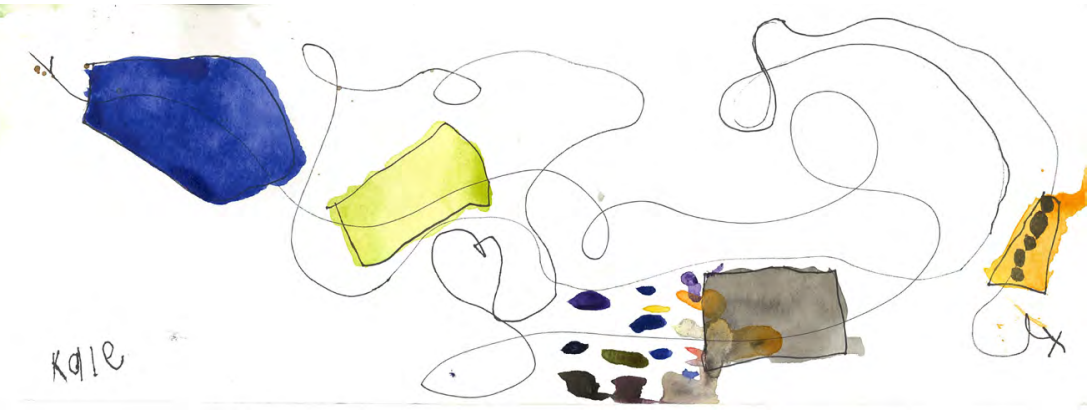

Figure 12. Pathways connecting the lakes to the community, by Kale.
There was a time when we looked to define learning expectations within children's play, but now we think about curriculum making as connecting to this ecological "web of life" (Malaguzzi, as cited by Filippini, 2018, n.p.) and we understand the need to stay with, and grapple with, the problems and issues presented within our local context and the world around us. This is distinctly relevant to Reggio's call to consider the environment 
and the future when researching with children. Reggio educators describe their research processes as "a way of thinking and as an approach to the future. A way of thinking of ourselves in relation to the world and in relation to life capable of creating the kind of innovation that can only be derived from research" (Reggio Children, 2019, para. 2). This kind of research is important for innovating the way we think about our relationship to land.

Over time, as we have learned with the children and others and the land, and engaged in Reggio-inspired approaches, we have become more sensitive and are coming to understand that working from the idea of the human at the centre (sometimes described as the autonomous child, or child-centered approach) is complex-it is important to shifting dominant educational practices, but also privileges a problematic humancentric way of understanding the world. How do we view the land? Do we view the water as lacking agency? What if we centered the land in our education? How would an interdependent child learn? We see regeneration and the agency of nature when we visit the bush. Our perception of agency has shifted, from a humancentric perspective to one that is inclusive of the land, the water, and the life therein, and our questions are changing, from how does the child act on materials, to how do materials act on the child, and what does the land communicate to the children?

As Sophie has written elsewhere,

engagement with natural materials can promote a potentially radical epistemological shift when we take the opportunity to make ecological connections. A whole world-an ecological world-opens up when we make intentional connections to the emergence of these materials: their ecological connections, stories and contexts. (Edwards, 2017, p. 20)

\section{Resistance and creation: Drawing close to children and the land}

The adults and children have lots of discussions about what to do about the condition of the wild space. Do we clean it up by taking out the garbage? Sophie suggests that this doesn't solve the problem, because the garbage ends up in a landfill, and that we might consider other regenerative or recuperative pathways. We think about what is in the bush, what will decompose, and what could be reclaimed in a new and different way. Julie, along with a fellow teacher and the school principal, advocate with the central administration of the school board for action on the reclamation of this space in some form. Through this advocacy, they learn that the bush does not belong to the school or the board and that she, Sophie, Sharon, and the children have been trespassing. This space is owned by a developer whose permission is required to be in this place. The irony of Canada's relationship with Indigenous peoples is not lost on us. We were reminded as we listened to Elder Liz Akiwenzie (2018), knowledge keeper with Western University and the Ontario Provincial Centre of Excellence for Early Learning and Child Care, that this land is stolen land, dishonestly taken from Indigenous peoples. In the bush we see the problem that land ownership perpetuates. Private property, along with liability, are Western concepts, both of which, in broader and very localized terms, limit the capacity for engagement and learning on the land.

The legal and colonial idea of property has not diminished the children's connection to the bush; their empathy was deepened through our trespassed learning and listening. The children want to protect the bush.

Here we repeat the conclusions of the Reggio educators in Dialogues with Places:

The children's experience elicited empathetic, creative and cognitive processes, and generated project hypotheses aimed at opposing widespread attitudes of disengagement and indifference as well as passive and non-critical acceptance as spaces void of quality.

It would be a mistake to see this merely as an attitude of pleasant refinement, because today in every sphere, it is necessary to make choices. Our hope is that a sensitive approach to our surroundings can 
constitute a positive element with others and for participation and conscious solidarity with others and with that which surrounds us, an indispensable attitude for the future of democracy and humanity. (Reggio Children, 2008, p. 11)

Toward the end of the year, the children gather broken paving stones they have found partially buried and lay them one in front of the other. They begin to make a new pathway, one that follows a trail created by animals. We wonder, where will this pathway lead us?

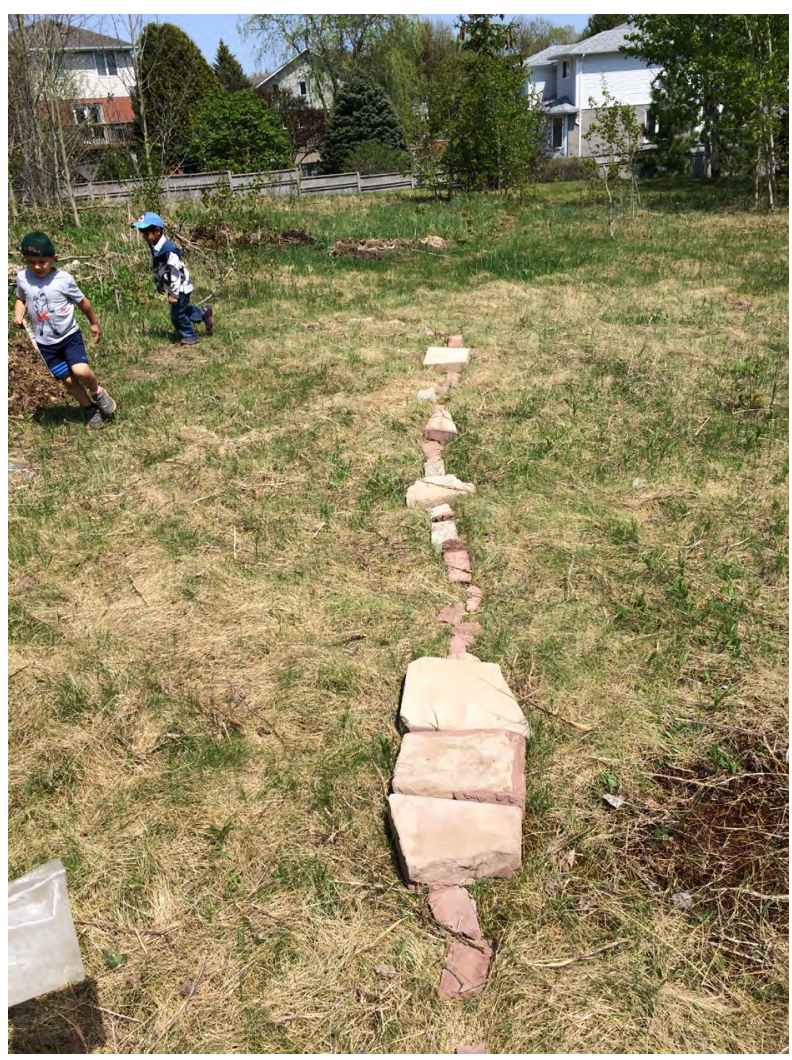

Figure 13. The children reimagine debris as a new paving stone pathway.

\section{Conclusion}

The children's path of listening (together with the adults) takes them in a direction that moves from dissatisfaction with the waste found in the bush (Zoe) to coordinating a response that respects this northern place, the aesthetics of its identity, and its troubled history, while gesturing toward the possibilities of different futures and ways of living together. Like the Dialogues with Places projects in the preschools of Reggio Emilia, the children are drawn to compose a gift to this place, and an invitation for others to join them in their encounters with the bush and the water.

It is clear from our experiences as teacher, artist, documenter, and children that learning on and with the land, from within our context, engenders distinctly relevant, revealing, and deep ecological and learning connections. This is a Reggio pathway we have followed in northern Ontario. 


\section{References}

Akiwenzie, L. (2018). Opening presentation of the 2018 Ontario Reggio Association Conference "Encounters with a Pedagogista: Colabouring Pedagogy as an Ethical Relationship," London, Ontario, October 13.

Dahlberg, G., \& Moss, P. (2005). Ethics and politics in early childhood education. Abingdon, UK: RoutledgeFalmer.

Edwards. C., Gandini, L., \& Forman, G. (Eds). (1998). The hundred languages of children: The Reggio Emilia approach-Advanced reflections. Westport, CT: Ablex.

Edwards, S. (2017). Land-based early learning: Introduction. In S. A. Edwards \& H. Thoma (Eds.), The art of land based early learning, Vol. 1: The emergence of natural materials and ecological connections (pp. 19-20). Kagawong, ON: 4elements Living Arts. *

Edwards, S. A., \& Thoma, H. (Eds). (2018). The art of land based early learning. Volume 11: The emergence of the artist, artwork, and community connections. Kagawong, ON: 4elements Living Arts. *

Filippini, T. (2018). Keynote presentation at the 2018 Ontario Reggio Association Conference "Encounters with a Pedagogista: Colabouring Pedagogy as an Ethical Relationship," London, Ontario, October 13.

Malaguzzi, L. (1994). Your image of the child: Where teaching begins. The Child Care Information Exchange, 3(94). Retrieved from https://www.reggioalliance.org/downloads/malaguzzi:ccie:1994.pdf

Neimanis, A. (2012). Thinking with water: An aqueous imaginary and an epistemology of unknowability. Paper presented at "Entanglements of New Materialisms," Linkoping, Sweden, May 25-26. Retrieved from https://www.academia.edu/1932447/Thinking_with_ Water_An_Aqueous_Imaginary_and_An_Epistemology_of_Unknowability

Reggio Children. (2008). Dialogue with places. Reggio Emilia, Italy: Preschools and Infant-Toddler Centers of the Municipality of Reggio Emilia \& Reggio Children.

Reggio Children. (2019). Research. Retrieved from https://www.reggiochildren.it/activities/ricerca/?lang=en

Rinaldi, C. (2003). The teacher as researcher. Innovations in Early Education: The International Reggio Exchange, 10(2), 1-4. Retrieved from https://apenet.files.wordpress.com/2011/01/researcher_rinaldi.pdf

${ }^{\star}$ Available from the authors. 